medRxiv preprint doi: https://doi.org/10.1101/2021.06.02.21258020; this version posted June 9, 2021. The copyright holder for this preprint (which was not certified by peer review) is the author/funder, who has granted medRxiv a license to display the preprint in perpetuity.

It is made available under a CC-BY 4.0 International license.

\title{
Neural asymmetry during memory encoding and its association with markers of preclinical Alzheimer's Disease
}

*Jinghang Li ${ }^{\mathrm{a}}$, *Elizabeth J. Mountz ${ }^{\mathrm{a}}$, Akiko Mizuno ${ }^{\mathrm{b}}$, Ashti M Shah ${ }^{\mathrm{c}}$, Andrea Weinstein ${ }^{\mathrm{b}}$, Ann D. Cohen $^{\text {b }}$ William E. Klunk ${ }^{\text {b, d }}$, Beth E. Snitz ${ }^{\text {, d }}$, Howard J. Aizenstein ${ }^{\mathrm{a}, \mathrm{b}}$, Helmet T. Karim ${ }^{\mathrm{a}, \mathrm{b}}$

\author{
Affiliations: \\ ${ }^{a}$ Department of Bioengineering, University of Pittsburgh, Pittsburgh, PA \\ ${ }^{\mathrm{b}}$ Department of Psychiatry, University of Pittsburgh, Pittsburgh, PA \\ ${ }^{\mathrm{c}}$ Physician Scientist Training Program, University of Pittsburgh School of Medicine, Pittsburgh, PA \\ ${ }^{\mathrm{d}}$ Department of Neurology, University of Pittsburgh, Pittsburgh, PA \\ * These authors contributed equally to this work.
}

\section{Corresponding author:}

Helmet T. Karim, PhD

Assistant Professor of Psychiatry and Bioengineering

University of Pittsburgh

Pittsburgh PA, 15213

Tel: (412) 246-6814

Email: hek26@pitt.edu

Keywords: Asymmetry, memory encoding, functional brain activation, Alzheimer's disease, amyloid

Acknowledgement: This study was supported by P50 AG005133, P01 AG025204, and R37 AG025516 from the National Institute of Health. We would also like to acknowledge and thank the GPN Lab for providing the research infrastructure and continuous mentorship that made this study possible.

Conflicts of interest: GE Healthcare holds a license agreement with the University of Pittsburgh based on the technology described in this manuscript. Dr. Klunk is a co-inventor of PiB and, as such, has a financial interest in this license agreement. GE Healthcare provided no grant support for this study and had no role in the design or interpretation of results or preparation of the manuscript. The other authors declare no conflicts of interest. 


\begin{abstract}
Background: Alzheimer's Disease (AD) is the most common form of dementia and is characterized by cognitive dysfunction that impacts daily functioning. Beta-amyloid $(\mathrm{A} \beta)$ is a cytotoxic protein that deposits in the brain many years prior to the onset of cognitive dysfunction. The preclinical period is a stage of $A D$ in which significant pathology is present without clinical symptoms. A $\beta$ has been shown to deposit asymmetrically early in the $\mathrm{AD}$ trajectory, which has shown to have functional consequences (e.g., asymmetric hypometabolism). We aimed to investigate whether markers of $\mathrm{AD}$ and cognitive function were correlated with neural activation asymmetry during memory encoding tasks.
\end{abstract}

Methods: We recruited participants who were cognitively normal to undergo functional magnetic resonance imaging (fMRI), positron emission tomography (PET) imaging, and cognitive testing. We conducted analyses to identify regions of significant activation during a well-established face-name pair memory encoding task, and to identify regions of significant asymmetry. We then computed hemispheric asymmetry (negative/positive values indicate left/right asymmetry, respectively) and absolute asymmetry (greater values indicate greater asymmetry in either hemisphere) and investigated their associations with age, sex, education, global cerebral amyloid, global cerebral metabolism, memory encoding task performance, white matter hyperintensities, and multiple domains of cognitive function.

Results: We identified expected regions of significant activation, including the hippocampus, and identified four regions with significant left-hemisphere asymmetry: superior medial frontal gyrus, middle frontal gyrus, supplemental motor area, and medial orbitofrontal gyrus, and two regions with significant right hemisphere asymmetry: putamen and ventral posterolateral nucleus of the thalamus. We found that greater left-hemisphere asymmetry in the middle frontal gyrus was correlated with greater global cerebral glucose metabolism. We also found that better performance in memory, learning, and executive attention was associated with greater absolute symmetry in the thalamus, while better visuospatial performance was associated with greater putamen absolute symmetry.

Discussion: Functional asymmetry is correlated with functional markers (e.g., glucose metabolism) in older cognitively normal adults and may reflect metabolic and cognitive changes. Longitudinal studies may help us better understand these associations and the causal impact of neural activation asymmetry. 


\section{INTRODUCTION}

Alzheimer's Disease (AD) is the leading cause of dementia, and is characterized by loss of memory and other cognitive functions earlier in the clinical disease process [1]. There is no known cure for AD, so understanding the mechanism of progression is key to early intervention. AD progression is associated with a gradual accumulation of neurofibrillary tangles, white matter hyperintensities (WMHs) [2], and amyloid beta $(A \beta)$ deposition [3]. Since the development of radioactive tracers like Pittsburgh Compound B (PiB), we can measure onset of $\mathrm{AD}$ pathology prior to onset of clinical symptoms [1]. This period in which a person has significant $\mathrm{A} \beta$ but no cognitive impairment is known as the preclinical stage of $\mathrm{AD}$ [1].

Previous research shows that $\mathrm{A} \beta$ may accumulate asymmetrically and is associated with asymmetric hypometabolism [4]. Other effects of significant $A \beta$ burden include reduced global glucose metabolism [5], atrophy [6], and functional changes in neuronal activity [4]. Generally, greater disease pathology in aging has also been shown to be associated with compensatory increases in neural activation and increased spread of activation. This phenomenon is referred to as dedifferentiation, defined as a loss of brain functional specificity [7]. Dedifferentiation is a postulated mechanism whereby additional neural resources are needed with accumulating cytotoxic protein and brain atrophy, which preserves behavioral function (e.g., cognitive function) for longer periods $[7,8]$.

Left-right hemispheric asymmetry is one measure of dedifferentiation; however, the brain is naturally asymmetric such as left-hemispheric language dominance [9, 10]. Cross-sectional studies observing associations between extent of pathology and extent of functional asymmetry may help us better understand pathology-induced changes in neural activation [11, 12]. However, many studies that have delineated the age or pathology related dedifferentiation in cross-sectional settings by comparing older to younger adults. For example, one study found that greater symmetry of activation in the prefrontal regions was associated with older age in episodic memory encoding tasks, while only left lateralized activation was observed in younger adults performing the same tasks [13]. In $\mathrm{AD}$, extent of cerebral asymmetry is associated with lower cognitive function and greater disease severity [11]. Left hemispheric atrophy in cerebral volume specifically has been consistently identified by multiple studies in AD, and has been associated with worse prognosis, including greater AD pathology and lower cognitive function [11, 12]. These may indicate that compensatory mechanisms have an upper limit, and asymmetry is not necessarily inherently a marker of disease.

To our knowledge, previous studies have not evaluated neural activation asymmetry in the preclinical phases of AD. We measured neural activity during a well-established memory encoding task [14] and identified regions of significant asymmetry. We then evaluated associations between AD factors and asymmetric activations. We hypothesized that greater left-lateralized activation would be associated with greater $\mathrm{AD}$-related pathology (less $\mathrm{A} \beta$ deposition and $\mathrm{WMHs}$ and greater global glucose metabolism) and task performance.

\section{METHODS}

\section{Participants and Study Design}

We recruited 87 participants who were cognitively normal to undergo magnetic resonance (MR) imaging and positron emission tomography (PET) imaging. We included participants who were $>65$ years of age, fluent in English, and whose cognitive function was normal. Clinical impairment (MCI) was assessed using methods consistent with those used at the University of Pittsburgh Alzheimer Disease Research Center. The criteria for MCI included performance on the neurocognitive assessments below expectations $(>1$ 
standard deviation below age and education adjusted norms) on at least 2 tests within the same domain, or at least three tests across domains, reports from the participant of changes or concerns about memory or cognition, and behavioral observations by staff. Results were reviewed by blinded neuropsychologists (BES) and geriatric psychiatrists (WEK and HJA), and each clinical diagnosis was reached by consensus. We excluded participants with diagnoses of mild cognitive impairment or dementia, history of major psychiatric or neurologic disorders, unstable medical conditions, sensory deficits that would preclude cognitive testing, contraindications to MRI, or who were on medications that could affect cognitive function. This study was approved by the University of Pittsburgh Institutional Review Board, and participants gave written informed consent prior to participating in the study. In this analysis, we focus on baseline visits (as this was part of a larger longitudinal study).

\section{$\underline{\text { Neurocognitive Assessments }}$}

All participants went through a series of neuropsychological tests used by the University of Pittsburgh Alzheimer Disease Research Center (ADRC) to assess cognitive function. For each neuropsychological test conducted, we combined the test scores into domain composite z-scores calculated using the sample averages, which reflected cognitive function in memory (Logical Memory $1 \& 2$ from the Wechsler Memory Scale - Revised, Modified Rey-Osterreith [R-O] Figure recall, Consortium to Establish a Registry for Alzheimer Disease [CERAD] Word List Memory Test); visuospatial function (Wechsler Adult Intelligence Scale-Revised [WAIS-R] Block Design, Modified R-O Figure copy); language (Animal and Letter Fluency, the 60-Item Boston Naming Test); and executive attention (Trail Making Test A and B, Clock Drawing, WAIS-R Maximum Digit Span Forward and Backward, paper and pencil version of the Stroop Interference Score, and WAIS-R Digit Symbol Substitution) [15][16]. Additionally, the memory domain was split into learning (immediate recall of the listed tests) and retrieval (delayed recall) to isolate the role of the prefrontal cortex in delayed memory retrieval. The z-scores of all tests within each domain were averaged to calculate a standard cognitive domain score.

\section{MRI Acquisition}

MR data was collected on a $3 \mathrm{~T}$ Siemens Trio scanner using a 12-channel head coil located at the MR Research Center at the University of Pittsburgh. We collected a high resolution structural T1-weighted magnetization prepared rapid gradient echo (MPRAGE) with repetition time $(\mathrm{TR})=2300 \mathrm{~ms}$, echo time $(\mathrm{TE})=900 \mathrm{~ms}$, flip angle $=9^{\circ}, \mathrm{FOV}=256 \times 224 \mathrm{~mm}, 176$ slices, and $1-\mathrm{mm}$ isotropic voxels. We acquired a T2*-weighted blood oxygen-level-dependent (BOLD) during the face-name pair encoding task with gradient-echo echo-planar imaging with $\mathrm{TR}=2000 \mathrm{~ms}, \mathrm{TE}=34 \mathrm{~ms}, \mathrm{FOV}=128 \times 128,28$ slices, and $2 \times 2 \times 4 \mathrm{~mm}$ voxel size. T2-weighted fluid-attenuated inversion recovery (FLAIR) was acquired with $\mathrm{TR}=9160 \mathrm{~ms}, \mathrm{TE}=90 \mathrm{~ms}$ [effective], inversion time $(\mathrm{TI})=2500 \mathrm{~ms}, \mathrm{FOV}=212 \times 256,48$ slices, and $1 \times 1 \times 3 \mathrm{~mm}$ resolution with no slice gap. MR scanning lasted approximately one hour as other sequences were run (not reported).

\section{Face-Name Pair Memory Encoding Task}

The face-name memory encoding task is known to reliably activate areas like the hippocampus and dorsolateral prefrontal cortex [17]. The face-name task has been widely studied in AD progression as a memory encoding task [14]. For the face-name task, participants are first shown two face-name pairs outside of the MR scanner. These serve as the control face-name pairs. During the task in the scanner, using a block design ( 8 face-name pairs for each block), participants were shown either the control face-name pairs or novel face-name pairs and were asked to make subjective judgements about whether the name shown "fits" the face (Figure 1). While in the scanner, new face-name pairs were shown to the participants and were actively encoded within the scanner. Blocks of familiar and new face-name pairs were alternated. 
medRxiv preprint doi: https://doi.org/10.1101/2021.06.02.21258020; this version posted June 9, 2021. The copyright holder for this preprint (which was not certified by peer review) is the author/funder, who has granted medRxiv a license to display the preprint in perpetuity. It is made available under a CC-BY 4.0 International license .

The new face-name pairs that the participants encountered in the scanner were the novel state, and the familiar faces-name pairs were the control state. Both novel and control state activation values were measured with reference to a resting state, during which the participant focused on white crosshairs on a dark screen. Outside of the scanner, participants were shown those same faces and two potential names and were asked to identify the one they saw in the scanner. Post-scan accuracy was computed as the percent of face-name pairs accurately encoded during the face-name task.

\section{$\underline{\text { Structural Image Processing }}$}

Structural images were co-registered to the MPRAGE then segmented using SPM12 multispectral segmentation that generates a deformation field which can be used to normalize functional imaging data to MNI space. We then threshold probability maps of gray matter, white matter, and cerebrospinal fluid by 0.1 and conducted image filling and closing using MATLAB functions to generate an intracranial volume (ICV) mask. MPRAGE images were skull stripped to improve co-registration with functional imaging data. Participants' WMHs were quantified using a semi-automatic fuzzy connectedness algorithm that segments T2-FLAIR images [18]. All segmentations were reviewed manually to ensure appropriate segmentation.

\section{Functional Image Processing}

The functional image processing was done using SPM12. We conducted motion correction, co-registration to the skull stripped MPRAGE, normalization to MNI space (using deformation field generated in structural processing), and then spatial smoothing using a Gaussian kernel of full width at half-maximum of $8 \mathrm{~mm}$. The novel and control condition effects were modeled using boxcars of onsets and durations convolved with the hemodynamic response function using a general linear model. We included a high-pass filter $(1 / 128 \mathrm{~Hz})$ to account for drift and an autoregressive [AR(1)] model to account for serial correlations due to aliased biorhythms or unmodeled activity. The contrast novel minus control was generated for group level analyses.

\section{PET Data Acquisition and Analysis}

PiB-PET acquisition and analysis utilized previously described and validated approach [19]. PiB was injected intravenously (12-15mCi, over $20 \mathrm{~s}$, specific activity $1-2 \mathrm{Ci} / \mu \mathrm{mol})$ and PET acquisition occurred over the 50-70 min post-injection period. MR images were used for co-registration and region of interest definitions which utilized FreeSurfer segmentation. Standardized uptake value ratios (SUVR) were calculated as the ratio of regional $\mathrm{PiB}$ to that of cerebellar gray matter correcting for cerebral atrophy. Global PiB was calculated as the average of nine regions defined within FreeSurfer: anterior cingulate, anterior ventral striatum, superior frontal, orbitofrontal, insula, lateral temporal, parietal, posterior cingulate, and precuneus. We divided these participants into groups of high and low PiB using a median split for statistical power.

Global glucose metabolism was measured using fluorodeoxyglucose (FDG) tracer and PET imaging, which we have described in past work [5]. A similar approach was used to compute global cerebral glucose metabolism as we did for PiB. FDG SUVR was calculated for each of the nine regions at 40-60 minutes post-injection and corrected for cortical atrophy. Global cerebral metabolism was the average of the nine regions. 


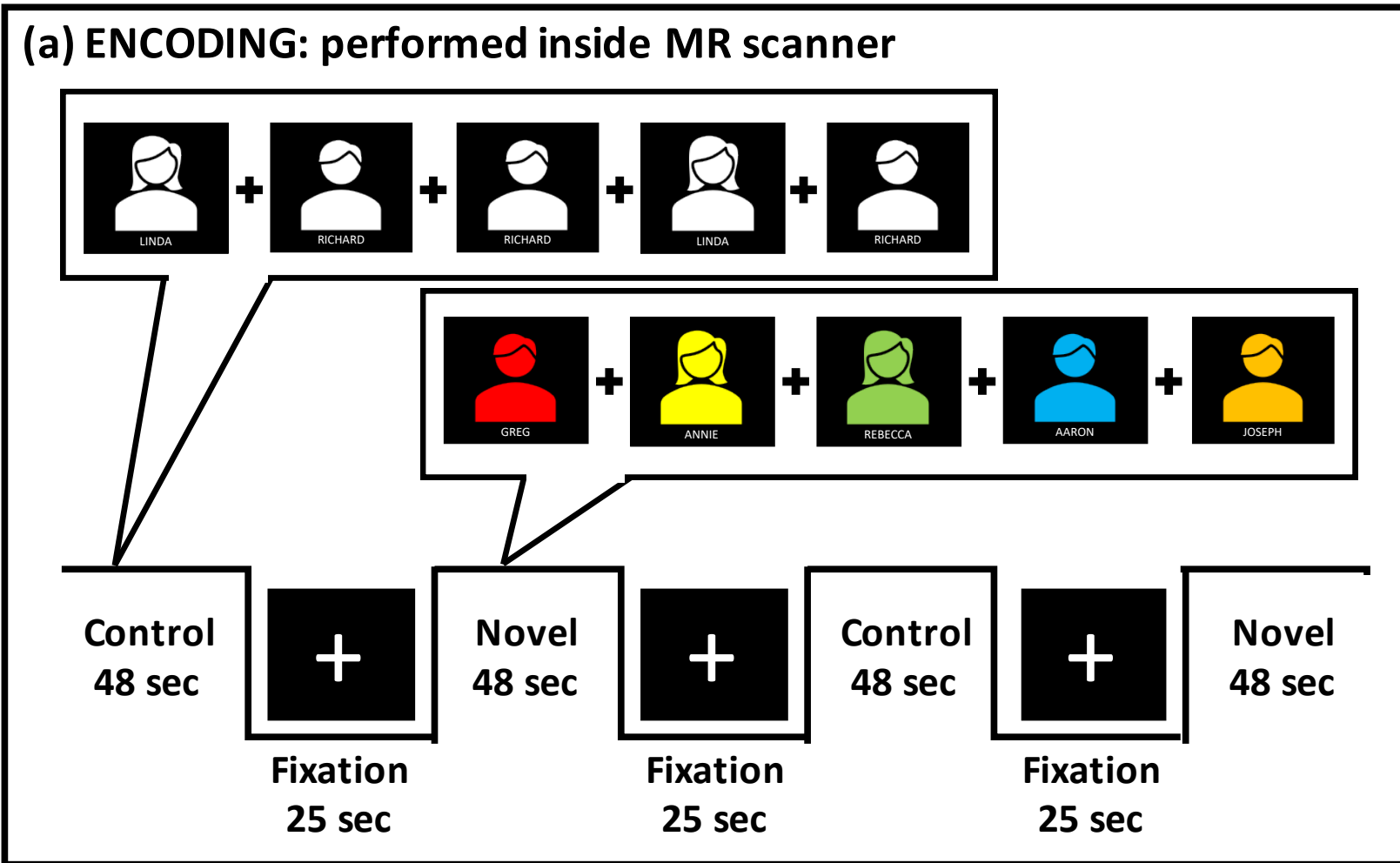

(b) RECALL: performed after MR scan

\section{"Choose the name that was shown with the face."}
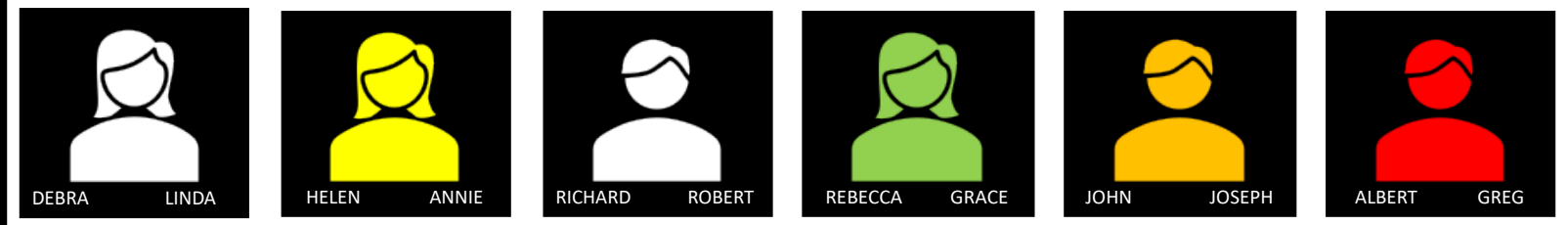

Figure 1. The face-name pair memory encoding task. Prior to the task, participants were shown two control face-name pairs (one male and one female, shown in white), which they were asked to remember. During the fMRI scan, participants were shown both novel (shown in color) and familiar (i.e., control shown in white) face-name pairs, so that novel pairs were actively encoded in the scanner (a). They were instructed to remember the face-name pairs and to answer whether the name fits the face being shown (they were also told that they were going to be tested after the scan). Activation values during both novel and control conditions were measured relative to activation values during the fixation periods, during which the participant focuses on white crosshairs. After the scan, participants were shown the faces seen in the scanner (total of 50 faces) and asked to choose between two names (one of which is the correct name), assessing encoding performance (b) [4]. Approximately 21 cues were non-white faces (42\%) and half were female sex. 


\section{$\underline{\text { Statistical Analysis }}$}

We used Statistical non-Parametric Mapping (SnPM) to conduct group level analyses, which computes non-parametric p-values using permutation testing (10,000 permutations used). We first conducted a paired t-test between novel and control conditions in all participants to identify regions of significant activation during the novel compared to the control condition. We used a cluster forming threshold of $p=0.001$ and corrected for multiple comparisons by controlling the cluster family-wise error (FWE) rate at 0.05 . This analysis excluded 17 participants whose coverage was poor in the motor cortex, supplemental motor area, or frontal cortex. Our analysis included 70 participants with full coverage, but data was excluded pairwise for all analyses.

We then generated a mask of voxels that were significantly active in at least one hemisphere during the face-name task. We divided all functional clusters using structural definitions from the automated anatomic labeling (AAL3) atlas [20]. We extracted activation (novel-control condition) in each region on the left and right hemisphere (note that all regions have similar number of voxels in the left and right hemisphere). To identify regions that have significant asymmetry, we conducted paired t-tests on the novelcontrol values of each region between the left and right hemisphere. We controlled the false-discovery rate (FDR) at 0.05 [21].

For regions with significant asymmetry, we computed two markers of asymmetry [22]. We first computed directional asymmetry, which is the difference of the left and the right average activation divided by the sum of the absolute value of the left and the right average activation (novel-control). Positive values indicate greater left-hemisphere dominance while negative values indicate greater right-hemisphere dominance and zero indicates perfect symmetry. We then computed the absolute value of asymmetry such that positive values reflect asymmetry in either the left or right hemisphere and zero indicates perfect symmetry. Absolute asymmetry reflects asymmetry in either hemisphere and represents symmetry vs. lack of symmetry.

In regions with significant asymmetry, we tested their association with factors related to AD. To assess the relationship between $\mathrm{AD}$ factors and functional asymmetry in each region, we tested the Pearson's correlation between asymmetry or absolute asymmetry and the following: task performance (as indicated by post-scan retrieval), cerebral glucose metabolism, white matter hyperintensities (WMH), age, and education. Additionally, we adjusted the WMH correlation test for each participant's total intracranial volume. We conducted independent t-tests (two-tailed) on asymmetry or absolute asymmetry between $\mathrm{PiB}$ groups and sex. Within each analysis, we controlled the False Discovery Rate at 0.05 across all regions. All analyses included only available data (i.e., removed incomplete data with no imputation). We repeated these analyses across domains of cognitive function correcting for multiple corrections by controlling the FDR at 0.05 .

\section{$\underline{\text { RESULTS }}$}

Table 1 shows group differences between high and low PiB (median split). We found that the high PiB group had fewer years in education compared to the low PiB group but did not differ in other values including cognitive function.

We first identified regions of statistically significant activation during the face-name task using a voxel-wise whole brain paired t-test (see Figure $2 \mathrm{a}$ and Table 2). We identified significant activation in the pregenual anterior cingulate, middle and posterior cingulate, inferior frontal gyrus (inferior operculum, 
medRxiv preprint doi: https://doi.org/10.1101/2021.06.02.21258020; this version posted June 9, 2021. The copyright holder for this preprint (which was not certified by peer review) is the author/funder, who has granted medRxiv a license to display the preprint in perpetuity.

It is made available under a CC-BY 4.0 International license .

orbital, triangular, and medial orbital), middle frontal gyrus, superior frontal gyrus, superior medial frontal gyrus, orbitofrontal gyrus (anterior, lateral, and posterior), amygdala, hippocampus, insula, parahippocampus, putamen, red nucleus, substantia nigra (pars reticulata), nuclei of the thalamus (magnocellular portion of the mediodorsal nucleus), medial pulvinar nucleus, ventral lateral nucleus, and ventral posterolateral nucleus), olfactory/rectus gyrus, temporal gyrus (inferior and superior pole), fusiform gyrus, visual cortex (calcarine, cuneus, lingual inferior occipital, and precuneus gyrus), supplemental motor area, cerebellar lobe IV-V (sensorimotor), and Cerebellar lobe VI (mental imagery).

\begin{tabular}{|c|c|c|c|c|c|c|}
\hline & $\begin{array}{l}\text { Whole Group } \\
\quad(\mathrm{N}=70)\end{array}$ & $\begin{array}{l}\text { High PiB } \\
(\mathrm{N}=27)\end{array}$ & $\begin{array}{l}\text { Low PiB } \\
(\mathrm{N}=27)\end{array}$ & & & \\
\hline & Mean (SD) [\#N missing] & \multicolumn{2}{|c|}{ Mean (SD) [\#N missing] } & & & \\
\hline & $\mathrm{N}(\%)$ & \multicolumn{2}{|c|}{$\mathrm{N}(\%)$} & 95\% CI for Mean Difference & Test Statistic (df) & p Value \\
\hline Age (years) & $75(6)[\mathrm{n}=8$ missing $]$ & $76.1(6.2)$ & $74.3(5.6)$ & $(-1.49,5.02)$ & $\mathrm{t}(50.7)=1.09$ & 0.28 \\
\hline Sex (Male) & $23(36 \%)[n=6$ missing $]$ & $7(26 \%)$ & $12(46 \%)$ & N/A & $\mathrm{x}(1)=1.56$ & 0.21 \\
\hline Race (White) & $50(78 \%)[\mathrm{n}=14$ missing $]$ & $24(89 \%)$ & $24(89 \%)$ & $\mathrm{N} / \mathrm{A}$ & $x(2)=0.98$ & 0.61 \\
\hline Education (years) & $15(2)[\mathrm{n}=14$ missing $]$ & $14.3(2.0)$ & $15.5(2.6)$ & $(-0.01,2.57)$ & $t(47.5)=2.0$ & $0.05^{*}$ \\
\hline Global PiB (SUVR) & $1.5(0.55)[\mathrm{n}=16$ missing $]$ & $1.8(0.68)$ & $1.3(0.05)$ & $(0.28,0.82)$ & $\mathrm{N} / \mathrm{A}$ & N/A \\
\hline FDG (Fludeoxyglucose) & $1.6(0.13)[\mathrm{n}=16$ missing $]$ & $1.62(0.10)$ & $1.62(0.15)$ & $(-0.07,0.07)$ & $\mathrm{t}(47.4)=0.04$ & 0.97 \\
\hline WMHI (White Matter Hyperintensity) & $2.8(5.44)[n=21$ missing $]$ & $2.12(2.72)$ & $3.53(7.03)$ & $(-1.64,4.44)$ & $\mathrm{t}(34)=0.94$ & 0.35 \\
\hline Post Scan Accuracy & $0.7(0.11)[\mathrm{n}=1$ missing $]$ & $0.67(0.12)$ & $0.69(0.11)$ & $(-0.04,0.08)$ & $\mathrm{t}(50.2)=0.62$ & 0.54 \\
\hline Memory Learning & $0.00(0.65)[\mathrm{n}=8$ missing $]$ & $0.00(0.80)$ & $0.00(0.63)$ & $(-0.42,0.31)$ & $\mathrm{t}(50)=-0.30$ & 0.77 \\
\hline Memory Retrieval & $0.00(0.68)[\mathrm{n}=8$ missing $]$ & $0.00(0.97)$ & $0.00(0.62)$ & $(-0.17,0.58)$ & $\mathrm{t}(48.2)=1.08$ & 0.28 \\
\hline Visuospatial & $0.00(0.69)[\mathrm{n}=8$ missing $]$ & $0.00(0.89)$ & $0.00(0.67)$ & $(-0.30,0.48$ & $t(50.4)=0.45$ & 0.66 \\
\hline Language & $0.00(0.75)[\mathrm{n}=8$ missing $]$ & $0.00(0.85)$ & $0.00(0.78)$ & $(-0.36,0.51)$ & $\mathrm{t}(45.1)=0.35$ & 0.73 \\
\hline Executive Attention & $0.00(0.59)[\mathrm{n}=9$ missing $]$ & $0.00(0.57)$ & $0.00(0.58)$ & $(-0.14,0.51)$ & $\mathrm{t}(49.6)=1.15$ & 0.25 \\
\hline \multicolumn{7}{|c|}{ Memory Learning } \\
\hline Logical Memory Immediate & $15.9(3.5)[\mathrm{n}=8$ missing $]$ & $16.1(3.5)$ & $16.2(3.6)$ & $(-1.88,2.04)$ & $\mathrm{t}(50.8)=0.08$ & 0.93 \\
\hline Modified Rey-Osterreith Figure Immediate & $16.5(3.0)[\mathrm{n}=8$ missing $]$ & $16.2(3.2)$ & $16.5(2.9)$ & $(-1.34-2.02)$ & $t(50.7)=0.40$ & 0.69 \\
\hline ADRC Word List Immediate** & $20.8(3.6)[\mathrm{n}=8$ missing $]$ & $21.6(4.0)$ & $20.6(3.0)$ & $(-3.0-0.89)$ & $t(47.9)=-1.09$ & 0.28 \\
\hline \multicolumn{7}{|c|}{ Memory Retrieval } \\
\hline Logical Memory Delayed & $15.1(3.7)[\mathrm{n}=8$ missing $]$ & $15.5(4.2)$ & $14.8(3.6)$ & $(-2.79-1.52)$ & $t(50.5)=-0.59$ & 0.56 \\
\hline Modified Rey-Osterreith Figure Delayed & $16.2(3.1)[\mathrm{n}=8$ missing $]$ & $16.4(3.2)$ & $16.1(3.1)$ & $(-2.04-1.41)$ & $t(51.0)=-0.36$ & 0.72 \\
\hline ADRC Word List Delayed & $7.3(2.0)[\mathrm{n}=8$ missing $]$ & $7.8(2.1)$ & $7.1(1.7)$ & $(-1.7-0.39)$ & $t(49.6)=-1.26$ & 0.21 \\
\hline \multicolumn{7}{|c|}{ Visuospatial } \\
\hline Block Design & $14.5(3.9)[\mathrm{n}=8$ missing $]$ & $14.7(4.5)$ & $14.9(3.5)$ & $(-2.02-2.38)$ & $t(48.8)=0.17$ & 0.87 \\
\hline Modified Rey-Osterreith Figure Copy & $19.6(2.2)[\mathrm{n}=8$ missing $]$ & $19.3(2.4)$ & $19.6(2.1)$ & $(-0.97-1.53)$ & $t(50.4)=0.45$ & 0.65 \\
\hline \multicolumn{7}{|c|}{ Language } \\
\hline Animal Fluency & $20.3(5.2)[\mathrm{n}=8$ missing $]$ & $20.3(6.1)$ & $20.1(4.9)$ & $(-3.25-2.82)$ & $t(49.5)=-0.14$ & 0.89 \\
\hline Letter Fluency*** & $14.2(4.3)[\mathrm{n}=8$ missing $]$ & $14.7(4.6)$ & $14.2(3.9)$ & $(-2.77-1.92)$ & $t(50.1)=-0.36$ & 0.72 \\
\hline 60-Item Boston Naming Test & $56.3(4.1)[\mathrm{n}=8$ missing $]$ & $55.7(4.4)$ & $57.2(3.7)$ & $(-0.74-3.72)$ & $t(49.9)=1.34$ & 0.19 \\
\hline \multicolumn{7}{|c|}{ Executive Attention } \\
\hline Trail-Making Test A & $29.8(10.3)[\mathrm{n}=8$ missing $]$ & $29.8(8.8)$ & $30.1(12.2)$ & $(-5.7-6.1)$ & $t(45.1)=0.08$ & 0.93 \\
\hline Trail-Making Test B & $81.2(34.1)[\mathrm{n}=8 \mathrm{missing}]$ & $79.7(36.7)$ & $74.8(24.3)$ & $(-22.1-12.3)$ & $t(45.4)=-0.57$ & 0.57 \\
\hline Clock Drawing & $14.3(0.74)[\mathrm{n}=8$ missing] & $14.2(0.89)$ & $14.4(0.58)$ & $(-0.21-0.61)$ & $t(44.7)=0.98$ & 0.33 \\
\hline Maximum Digit Span Forward & $6.7(0.9)[\mathrm{n}=8$ missing $]$ & $6.5(0.9)$ & $6.9(1.0)$ & $(-0.10-0.98)$ & $t(50.2)=1.64$ & 0.11 \\
\hline Maximum Digit Span Backward & $4.9(1.2)[\mathrm{n}=8$ missing $]$ & $4.67(1.2)$ & $5.23(1.2)$ & $(-0.09-1.2)$ & $t(51.0)=1.72$ & 0.09 \\
\hline Stroop Interference Score**** & $-0.94(6.6)[\mathrm{n}=9$ missing] & $-1.74(6.7)$ & $-0.32(7.0)$ & $(-2.35-5.20)$ & $t(50.6)=0.76$ & 0.45 \\
\hline Digit Symbol Substitution & $51.0(10.9)[\mathrm{n}=8$ missing $]$ & $53.1(10.8)$ & $50.4(11.0)$ & $(-8.70-3.32)$ & $t(50.8)=-0.90$ & 0.37 \\
\hline \multicolumn{7}{|c|}{$\begin{array}{l}\text { Note: } \\
* \mathrm{p}<0.05 . \text { We did not conduct a statistical test on Global PiB (SUVR) since this is how these groups were defined. The cognitive domain average is zero because all domain scores were normalized } \\
\text { by subtracting the mean then divided by the standard deviation. } \\
* * \text { ADRC Word List Immediate test results were the average of three individual ADRC Word List Immediate tests. } \\
* * * \text { Letter fluency is the average of test results for letters 'A', 'F', and 'S'. } \\
* * * * \text { Stroop Interference Score is calculated as the difference between Stroop Color/Word Test Results and Stroop Color/Word predicted test results. Predicted Stroop Color/Word results were } \\
\text { calculated as STRCOL*STRWRD / (STRCOL }+ \text { STRWRD), where STRCOL is the results from a test in which the participant names different colored patches, and STRWRD is results from a test } \\
\text { in which the participant reads names of colors written in black ink. }\end{array}$} \\
\hline
\end{tabular}


medRxiv preprint doi: https://doi.org/10.1101/2021.06.02.21258020; this version posted June 9, 2021. The copyright holder for this preprint (which was not certified by peer review) is the author/funder, who has granted medRxiv a license to display the preprint in perpetuity.

It is made available under a CC-BY 4.0 International license .

Table 2. Regions significantly activated by the memory encoding task (novel>control).

Separate clusters are separated by a gray bar. Each region was separated using the automated anatomical labeling 3 (AAL3) atlas. All clusters were significant after controlling the voxel-wise family-wise error (FWE) $<0.05$. The max $t-$ statistic (paired t-test), cluster size (in voxels), and MNI coordinates ( $x, y, z)$ are reported.

\begin{tabular}{|c|c|c|c|c|c|c|}
\hline Side & Region & Num. Voxels & T-statistic (max) & x MNI & y MNI & z MNI \\
\hline Left & Fusiform & 423 & 5.8 & -36 & -52 & -18 \\
\hline Left & \multirow{2}{*}{ Inferior Frontal (orbital) } & 394 & 5.8 & -44 & 30 & -12 \\
\hline Right & & 278 & 5 & 42 & 26 & -12 \\
\hline Left & \multirow{2}{*}{ Precuneus } & 311 & 5.9 & -4 & -54 & 20 \\
\hline Right & & 115 & 4.9 & 6 & -44 & 8 \\
\hline Left & \multirow{2}{*}{ Hippocampus } & 255 & 5.5 & -22 & -34 & -4 \\
\hline Right & & 74 & 5 & 20 & -10 & -12 \\
\hline Right & \multirow{2}{*}{ Lingual } & 253 & 5.2 & 4 & -38 & 2 \\
\hline Left & & 187 & 5.7 & -12 & -40 & -2 \\
\hline Right & \multirow{2}{*}{ Insula } & 239 & 4.3 & 48 & 16 & -2 \\
\hline Left & & 171 & 4.4 & -26 & 18 & -20 \\
\hline Bilateral & Vermis_4_5 & 230 & 5.8 & 0 & -42 & 2 \\
\hline Left & \multirow{2}{*}{ Orbitofrontal (posterior) } & 220 & 6.8 & -42 & 30 & -16 \\
\hline Right & & 168 & 5.9 & 42 & 28 & -14 \\
\hline Left & \multirow{2}{*}{ Cerebellum IV/V } & 210 & 5.8 & -6 & -40 & 0 \\
\hline Right & & 72 & 4 & 10 & -52 & -6 \\
\hline Left & Cerebellum VI & 126 & 5 & -28 & -56 & -18 \\
\hline Bilateral & Vermis VI & 120 & 4.7 & -2 & -74 & -12 \\
\hline Left & \multirow{2}{*}{ Posterior Cingulate } & 113 & 5.9 & -4 & -42 & 8 \\
\hline Right & & 72 & 5.9 & 2 & -40 & 8 \\
\hline Right & Ventral Posterolateral Nucleus Thalamus & 107 & 4.9 & 20 & -18 & 6 \\
\hline Left & \multirow{2}{*}{ Calcarine } & 98 & 5.4 & -6 & -44 & 6 \\
\hline Right & & 77 & 3.9 & 28 & -52 & 4 \\
\hline Left & \multirow{2}{*}{ Orbitofrontal (lateral) } & 95 & 6.6 & -44 & 30 & -14 \\
\hline Right & & 20 & 4.8 & 42 & 36 & -16 \\
\hline Right & Ventral Lateral Thalamus & 91 & 4.4 & 20 & -16 & 4 \\
\hline Left & Parahippocampus & 82 & 5.1 & -22 & -36 & -6 \\
\hline Left & \multirow{2}{*}{ Orbitofrontal (anterior) } & 77 & 6.3 & -36 & 36 & -16 \\
\hline Right & & 34 & 5.2 & 40 & 34 & -14 \\
\hline Right & \multirow{2}{*}{ Medial Pulvinar Nucleus Thalamus } & 59 & 4.2 & 14 & -30 & 2 \\
\hline Left & & 40 & 3.8 & -6 & -22 & 12 \\
\hline Right & \multirow{2}{*}{ Amygdala } & 57 & 4.9 & 24 & -6 & -16 \\
\hline Left & & 36 & 5.4 & -22 & -8 & -16 \\
\hline Right & \multirow{2}{*}{ Superior Temporal Pole } & 53 & 4.5 & 44 & 18 & -18 \\
\hline Left & & 25 & 4.6 & -48 & 22 & -12 \\
\hline Right & Inferior Frontal (triangular) & 50 & 4.1 & 48 & 20 & 0 \\
\hline Right & Inferior Frontal (operculum) & 47 & 4.4 & 50 & 16 & -2 \\
\hline Left & Inferior Temporal & 40 & 4.8 & -40 & -48 & -18 \\
\hline Left & Medial Mediodorsal Thalamus & 37 & 3.9 & -2 & -18 & 8 \\
\hline Right & Red Nucleus & 29 & 4.2 & 4 & -16 & -12 \\
\hline Right & Putamen & 23 & 3.7 & 28 & -12 & 6 \\
\hline Bilateral & Vermis III & 22 & 4.7 & 0 & -42 & -2 \\
\hline Right & Substantia Nigra (pars reticulata) & 22 & 4.1 & 14 & -10 & -10 \\
\hline Right & Fusiform & 193 & 5.9 & 36 & -46 & -18 \\
\hline Right & Inferior Temporal & 46 & 4.3 & 42 & -60 & -12 \\
\hline Right & Inferior Occipital & 35 & 5.3 & 38 & -64 & -12 \\
\hline
\end{tabular}


medRxiv preprint doi: https://doi.org/10.1101/2021.06.02.21258020; this version posted June 9, 2021. The copyright holder for this preprint (which was not certified by peer review) is the author/funder, who has granted medRxiv a license to display the preprint in perpetuity.

It is made available under a CC-BY 4.0 International license.

\begin{tabular}{|c|c|c|c|c|c|c|}
\hline \multicolumn{7}{|c|}{ Table 2 (Continued) } \\
\hline Side & Region & Num. Voxels & T-statistic (max) & $\mathbf{x}$ MNI & y MNI & z MNI \\
\hline Left & \multirow{2}{*}{ Medial Frontal (orbital) } & 269 & 5.7 & -4 & 46 & -14 \\
\hline Right & & 131 & 4.9 & 2 & 48 & -14 \\
\hline Left & \multirow{2}{*}{ Rectus gyrus } & 32 & 5.8 & -2 & 46 & -16 \\
\hline Right & & 29 & 5.4 & 2 & 50 & -16 \\
\hline Left & \multirow{2}{*}{ Cuneus } & 151 & 5.4 & 0 & -88 & 36 \\
\hline Right & & 42 & 4.5 & 6 & -94 & 20 \\
\hline Left & \multirow{2}{*}{ Superior Medial Frontal } & 1224 & 6.5 & -2 & 60 & 22 \\
\hline Right & & 380 & 5.3 & 2 & 62 & 16 \\
\hline Left & \multirow{2}{*}{ Superior Frontal } & 527 & 5.1 & -22 & 30 & 54 \\
\hline Right & & 299 & 4.4 & 14 & 56 & 28 \\
\hline Left & \multirow{2}{*}{ Supplemental Motor } & 173 & 4.4 & -4 & 22 & 46 \\
\hline Right & & 29 & 3.7 & 2 & 18 & 52 \\
\hline Left & Anterior Cingulate (pregenual) & 59 & 4.3 & -2 & 50 & 14 \\
\hline Right & Middle Frontal & 27 & 3.6 & 26 & 58 & 26 \\
\hline Left & Middle Frontal & 435 & 6.2 & -28 & 24 & 54 \\
\hline Left & Inferior Frontal (triangular) & 247 & 4.8 & -52 & 24 & 30 \\
\hline Left & Inferior Frontal (operculum) & 48 & 4.9 & -52 & 22 & 32 \\
\hline
\end{tabular}

We then found that there were six regions (after controlling FDR at 0.05) that had significant asymmetry (Table 3). Several regions had significant left hemisphere asymmetry: superior medial frontal gyrus, middle frontal gyrus, supplemental motor area, and medial orbitofrontal gyrus, while other regions had significant right hemisphere asymmetry: putamen and ventral posterolateral nucleus of the thalamus (see Figure 2b).

We conducted statistical analyses between asymmetry and multiple factors related to AD including global cerebral metabolism, global amyloid, WMH, task performance, age, sex, and education (Table 4). We found that greater global cerebral metabolism was correlated with greater left-hemisphere asymmetry in the middle frontal gyrus (Figure 3). We found no other significant associations. We found no association between absolute asymmetry and factors related to $\mathrm{AD}$, including global cerebral metabolism, global amyloid, WMH, task performance, age, sex, and education (Table 5).

We conducted statistical analyses between asymmetry and multiple cognitive domains (Table 6). We found that asymmetry was not significantly correlated to cognitive function. We repeated our analysis using absolute asymmetry and cognitive domains (Table 7). We found that better cognitive performance in memory learning and executive attention was correlated with lower absolute asymmetry in the ventral posterolateral thalamus (i.e., greater symmetry regardless of the direction [left or right]), while better visuospatial performance correlated with lower absolute asymmetry (i.e., greater symmetry) in the putamen. 
Table 3. All the regions below were significantly activated during DSST. Additionally, regions that were significantly and asymmetrically activated are bolded. The t-statistics, p-value and FDR corrected q-value are reported.

\begin{tabular}{|c|c|}
\hline Region & $\begin{array}{c}\text { t-test, p-value, FDR corrected q-value } \\
(\text { Positive }=\text { Left }>\text { Right })\end{array}$ \\
\hline Superior Medial Frontal & $t(69)=6.1, p=0, q=0$ \\
\hline Medial Frontal (orbital) & $\mathrm{t}(69)=4.1, p=0, q=0.002$ \\
\hline Middle Frontal & $t(69)=3.1, p=0.002, q=0.029$ \\
\hline Putamen & $\mathrm{t}(69)=-3.0, p=0.004, q=0.032$ \\
\hline Supplemental Motor & $t(69)=2.9, p=0.005, q=0.036$ \\
\hline Ventral Posterolateral Nucleus Thalamus & $t(69)=-2.8, p=0.007, q=0.04$ \\
\hline Cerebellum IV/V & $\mathrm{t}(69)=2.4, \mathrm{p}=0.018, \mathrm{q}=0.083$ \\
\hline Rectus gyrus & $\mathrm{t}(69)=2.4, \mathrm{p}=0.019, \mathrm{q}=0.083$ \\
\hline Precuneus & $\mathrm{t}(69)=2.3, \mathrm{p}=0.026, \mathrm{q}=0.088$ \\
\hline Inferior Occipital & $\mathrm{t}(69)=-2.3, \mathrm{p}=0.026, \mathrm{q}=0.088$ \\
\hline Cerebellum VI & $\mathrm{t}(69)=2.2, \mathrm{p}=0.033, \mathrm{q}=0.089$ \\
\hline Middle Cingulate & $\mathrm{t}(69)=2.2, \mathrm{p}=0.028, \mathrm{q}=0.088$ \\
\hline Superior Frontal & $\mathrm{t}(69)=2.2, \mathrm{p}=0.03, \mathrm{q}=0.088$ \\
\hline Orbitofrontal (anterior) & $\mathrm{t}(69)=2.1, \mathrm{p}=0.038, \mathrm{q}=0.089$ \\
\hline Orbitofrontal (lateral) & $\mathrm{t}(69)=2.1, \mathrm{p}=0.038, \mathrm{q}=0.089$ \\
\hline Superior Temporal Pole & $\mathrm{t}(69)=-2.0, \mathrm{p}=0.047, \mathrm{q}=0.103$ \\
\hline Inferior Temporal & $\mathrm{t}(69)=-1.8, \mathrm{p}=0.077, \mathrm{q}=0.154$ \\
\hline Ventral Lateral Thalamus & $\mathrm{t}(69)=-1.8, \mathrm{p}=0.079, \mathrm{q}=0.154$ \\
\hline Inferior Frontal (operculum) & $\mathrm{t}(69)=1.7, \mathrm{p}=0.093, \mathrm{q}=0.171$ \\
\hline Inferior Frontal (triangular) & $\mathrm{t}(69)=1.6, \mathrm{p}=0.121, \mathrm{q}=0.202$ \\
\hline Cuneus & $\mathrm{t}(69)=-1.6, \mathrm{p}=0.108, \mathrm{q}=0.189$ \\
\hline Anterior Cingulate (pregenual) & $\mathrm{t}(69)=1.5, \mathrm{p}=0.135, \mathrm{q}=0.215$ \\
\hline Medial Mediodorsal Thalamus & $\mathrm{t}(69)=1.4, \mathrm{p}=0.181, \mathrm{q}=0.264$ \\
\hline Medial Pulvinar Nucleus Thalamus & $\mathrm{t}(69)=-1.4, \mathrm{p}=0.155, \mathrm{q}=0.237$ \\
\hline Parahippocampus & $\mathrm{t}(69)=1.2, \mathrm{p}=0.24, \mathrm{q}=0.336$ \\
\hline Red Nucleus & $\mathrm{t}(69)=-0.9, \mathrm{p}=0.348, \mathrm{q}=0.468$ \\
\hline Insula & $\mathrm{t}(69)=-0.8, \mathrm{p}=0.419, \mathrm{q}=0.543$ \\
\hline Inferior Frontal (orbital) & $\mathrm{t}(69)=0.7, \mathrm{p}=0.508, \mathrm{q}=0.613$ \\
\hline Orbitofrontal (posterior) & $\mathrm{t}(69)=0.7, \mathrm{p}=0.482, \mathrm{q}=0.603$ \\
\hline Hippocampus & $\mathrm{t}(69)=0.4, \mathrm{p}=0.679, \mathrm{q}=0.792$ \\
\hline Posterior Cingulate & $\mathrm{t}(69)=-0.3, p=0.772, q=0.872$ \\
\hline Calcarine & $\mathrm{t}(69)=0.2, \mathrm{p}=0.866, \mathrm{q}=0.918$ \\
\hline Amygdala & $\mathrm{t}(69)=-0.2, \mathrm{p}=0.806, \mathrm{q}=0.881$ \\
\hline Lingual & $\mathrm{t}(69)=0.1, \mathrm{p}=0.939, \mathrm{q}=0.958$ \\
\hline Fusiform & $\mathrm{t}(69)=-0.1, \mathrm{p}=0.958, \mathrm{q}=0.958$ \\
\hline
\end{tabular}


medRxiv preprint doi: https://doi.org/10.1101/2021.06.02.21258020; this version posted June 9, 2021. The copyright holder for this preprint (which was not certified by peer review) is the author/funder, who has granted medRxiv a license to display the preprint in perpetuity.

It is made available under a CC-BY 4.0 International license .
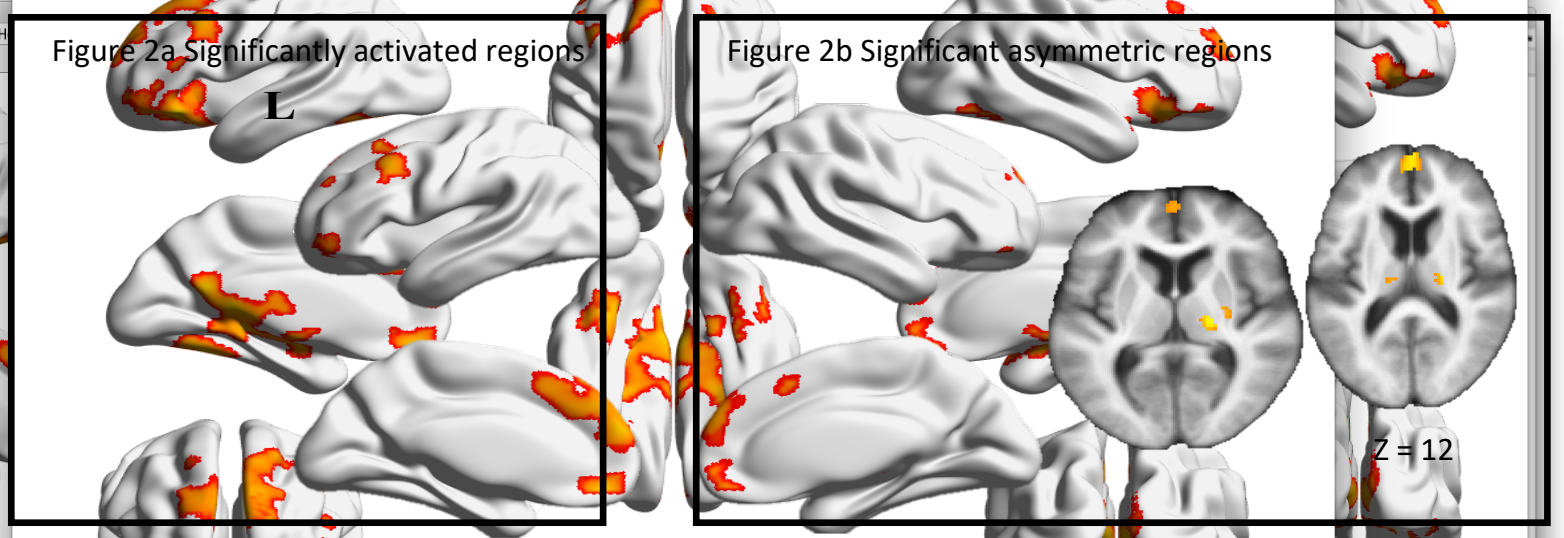

Figure 2. a) The areas that were significantly activated during the face-name memory encoding task (result of the voxel-wise paired t-test). b) The areas that were significantly asymmetric during the face-name memory encoding task. Generated using BrainNet viewer on a smoothed average brain template. In the last column, xjview was used to show thalamus and putamen regions.

\begin{tabular}{|c|c|c|c|c|c|c|c|}
\hline Region & $\begin{array}{c}\text { Global Cerebral } \\
\text { Metabolism }^{1} \\
\text { (FDG PET SUVR) }\end{array}$ & $\begin{array}{l}\text { Global Amyloid }^{2} \\
\quad(P i B S U V R)\end{array}$ & $\begin{array}{c}\mathrm{WMHI}^{3} \\
\text { (normalized by } \\
\text { ICV) }\end{array}$ & $\begin{array}{c}\text { Memory Encoding } \\
\text { Task Performance }^{1} \\
\text { (Accuracy) }\end{array}$ & $\begin{array}{l}\text { Age }^{1} \\
\text { (years) }\end{array}$ & $\begin{array}{c}\text { Sex }^{2} \\
\text { (reference group } \\
\text { Female) }\end{array}$ & $\begin{array}{c}\text { Education }^{1} \\
\quad \text { (years) }\end{array}$ \\
\hline \multirow{3}{*}{ Putamen } & $\mathrm{r}(52)=0.287$ & $\mathrm{t}(48.42)=0.118$ & $r(60)=0.123$ & $r(67)=0.175$ & $r(60)=-0.048$ & $\mathrm{t}(54.04)=1.909$ & $r(54)=-0.105$ \\
\hline & $\mathrm{p}=0.035^{*}$ & $\mathrm{p}=0.906$ & $\mathrm{p}=0.342$ & $\mathrm{p}=0.149$ & $\mathrm{p}=0.707$ & $\mathrm{p}=0.061^{*}$ & $\mathrm{p}=0.442$ \\
\hline & $q=0.105$ & $q=0.993$ & $q=0.943$ & $q=0.298$ & $\mathrm{q}=0.707$ & $q=0.185$ & $q=0.531$ \\
\hline \multirow{3}{*}{$\begin{array}{l}\text { Thalamus ventral } \\
\text { posterolateral nucleus }\end{array}$} & $\mathrm{r}(52)=0.247$ & $\mathrm{t}(49.49)=-0.305$ & $\mathrm{r}(60)=0.009$ & $\mathrm{r}(67)=0.253$ & $\mathrm{r}(60)=-0.240$ & $\mathrm{t}(40.25)=1.433$ & $\mathrm{r}(54)=0.110$ \\
\hline & $\mathrm{p}=0.071$ & $\mathrm{p}=0.761$ & $\mathrm{p}=0.943$ & $\mathrm{p}=0.036^{*}$ & $\mathrm{p}=0.060^{*}$ & $p-0.159$ & $\mathrm{p}=0.420$ \\
\hline & $q=0.142$ & $\mathrm{q}=0.993$ & $q=0.943$ & $\mathrm{q}=0.108$ & $\mathrm{q}=0.179$ & $q=0.276$ & $q=0.531$ \\
\hline \multirow{3}{*}{$\begin{array}{l}\text { Superior medial } \\
\text { frontal gyrus }\end{array}$} & $\mathrm{r}(52)=0.128$ & $\mathrm{t}(51.84)=-0.681$ & $r(60)=-0.245$ & $\mathrm{r}(67)=0.273$ & $r(60)=-0.307$ & $\mathrm{t}(33.41)=1.250$ & $\mathrm{r}(54)=-0.027$ \\
\hline & $\mathrm{p}=0.355$ & $\mathrm{p}=0.498$ & $\mathrm{p}=0.055^{*}$ & $\mathrm{p}=0.023 *$ & $\mathrm{p}=0.015^{*}$ & $p-0.220$ & $\mathrm{p}=0.844$ \\
\hline & $q=0.355$ & $q=0.993$ & $q=0.328$ & $q=0.108$ & $q=0.092$ & $q=0.276$ & $q=0.844$ \\
\hline \multirow{3}{*}{ Middle frontal gyrus } & $r(52)=0.342$ & $\mathrm{t}(51.86)=-0.137$ & $r(60)=-0.062$ & $r(67)=0.091$ & $r(60)=-0.154$ & $\mathrm{t}(44.96) .=2.058$ & $r(54)=-0.113$ \\
\hline & $\mathrm{p}=0.011^{*}$ & $\mathrm{p}=0.890$ & $\mathrm{p}=0.634$ & $\mathrm{p}=0.454$ & $\mathrm{p}=0.231$ & $\mathrm{p}-0.045^{*}$ & $\mathrm{p}=0.41$ \\
\hline & $q=0.068^{*}$ & $\mathrm{q}=0.993$ & $q=0.943$ & $\mathrm{q}=0.454$ & $\mathrm{q}=0.347$ & $\mathrm{q}=0.185$ & $q=0.531$ \\
\hline \multirow{3}{*}{ Supplemental motor area } & $\mathrm{r}(52)=0.149$ & $\mathrm{t}(47.70)=0.439$ & $r(60)=-0.077$ & $r(67)=-0.133$ & $\mathrm{r}(60)=0.116$ & $t(37.56)=1.219$ & $\mathrm{r}(54)=-0.151$ \\
\hline & $\mathrm{p}=0.283$ & $\mathrm{p}=0.662$ & $\mathrm{p}=0.549$ & $\mathrm{p}=0.277$ & $\mathrm{p}=0.368$ & $\mathrm{p}=0.230$ & $\mathrm{p}=0.267$ \\
\hline & $q=0.339$ & $q=0.993$ & $q=0.943$ & $q=0.332$ & $\mathrm{q}=0.441$ & $q=0.276$ & $q=0.531$ \\
\hline \multirow{3}{*}{ Medial orbitofrontal gyrus } & $r(52)=0.152$ & $\mathrm{t}(49.38)=-0.009$ & $r(60)=0.015$ & $\mathrm{r}(67)=0.151$ & $\mathrm{r}(60)=-0.199$ & $\mathrm{t}(35.19)=-0.360$ & $\mathrm{r}(54)=0.225$ \\
\hline & $\mathrm{p}=0.273$ & $\mathrm{p}=0.993$ & $\mathrm{p}=0.910$ & $\mathrm{p}=0.214$ & $\mathrm{p}=0.120$ & $\mathrm{p}=0.721$ & $\mathrm{p}=0.096$ \\
\hline & $q=0.339$ & $\mathrm{q}=0.99$ & $q=0.943$ & $\mathrm{q}=0.321$ & $\mathrm{q}=0.240$ & $\mathrm{q}=0.721$ & $\mathrm{q}=0.531$ \\
\hline
\end{tabular}


medRxiv preprint doi: https://doi.org/10.1101/2021.06.02.21258020; this version posted June 9, 2021. The copyright holder for this preprint (which was not certified by peer review) is the author/funder, who has granted medRxiv a license to display the preprint in perpetuity.

\section{Global Cerebral Metabolism Correlation with Middle Frontal Gyrus Asymmetry}

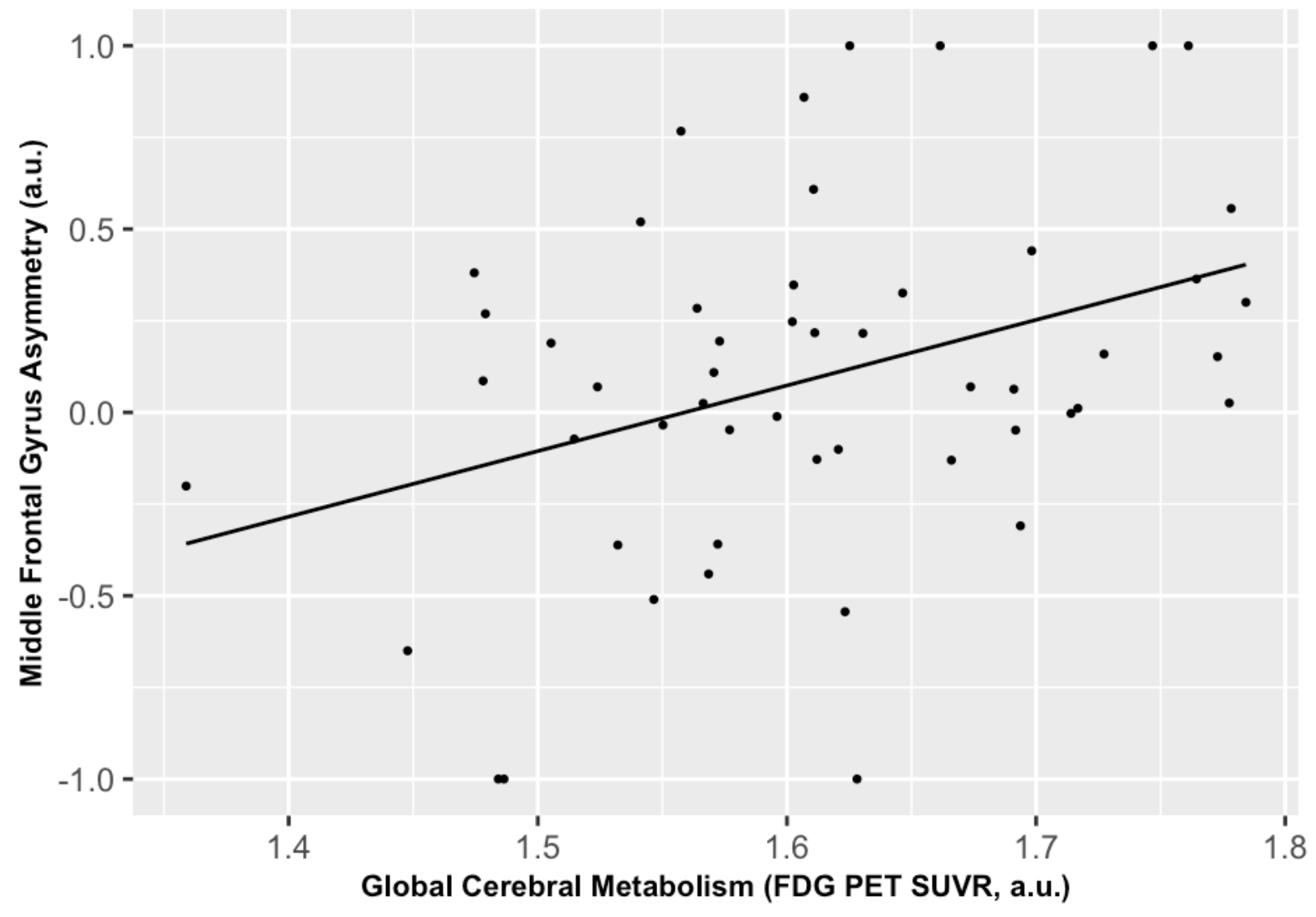

Figure 3. Association between greater global cerebral metabolism (FDG PET SUVR) and greater lefthemisphere asymmetry in the middle frontal gyrus $[r(52)=0.342, p=0.011, q=0.068]$.

Table 5. Associations between functional absolute Asymmetry and AD Factors. We report the statistical test (1-Pearson's correlation, 2-Independent t-test, and 3Partial Pearson's Correlation), degrees of freedom, and p-values as well as the adjusted q-value from the FDR correction (correcting across 6 regions per set of 6 tests).

\begin{tabular}{|c|c|c|c|c|c|c|c|}
\hline Region & $\begin{array}{c}\text { Global Cerebral } \\
\text { Metabolism }^{1} \\
\text { (FDG PET SUVR) }\end{array}$ & $\begin{array}{l}\text { Global Amyloid }^{2} \\
\quad(P i B \text { SUVR })\end{array}$ & $\begin{array}{c}\mathrm{WMHI}^{3} \\
\text { (normalized by } \\
\text { ICV) } \\
\end{array}$ & $\begin{array}{c}\text { Memory Encoding } \\
\text { Task Performance }^{1} \\
\text { (Accuracy) }\end{array}$ & $\begin{array}{l}\text { Age }{ }^{I} \\
\text { (years) }\end{array}$ & $\begin{array}{c}\text { Sex }^{2} \\
\text { (reference group } \\
\text { Female) } \\
\end{array}$ & $\begin{array}{c}\text { Education } \\
\text { (years) }\end{array}$ \\
\hline \multirow{3}{*}{ Putamen } & $\mathrm{r}(52)=-0.210$ & $\mathrm{t}(51.88)=1.71$ & $\mathrm{r}(60)=0.134$ & $r(67)=-0.080$ & $\mathrm{r}(60)=0.147$ & $\mathrm{t}(45.23)=-0.335$ & $r(54)=-0.026$ \\
\hline & $\mathrm{p}=0.127$ & $\mathrm{p}=0.906$ & $\mathrm{p}=0.299$ & $\mathrm{p}=0.515$ & $\mathrm{p}=0.254$ & $\mathrm{p}=0.739$ & $\mathrm{p}=0.847$ \\
\hline & $\mathrm{q}=0.381$ & $q=0.993$ & $q=0.477$ & $q=0.871$ & $q=0.926$ & $q=0.739$ & $q=0.986$ \\
\hline \multirow{3}{*}{$\begin{array}{l}\text { Thalamus ventral } \\
\text { posterolateral nucleus }\end{array}$} & $\mathrm{r}(52)=-0.107$ & $\mathrm{t}(51.85)=1.58$ & $r(60)=-0.092$ & $r(67)=-0.179$ & $r(60)=-0.056$ & $t(42.67)=-1.538$ & $\mathrm{r}(54)=0.016$ \\
\hline & $\mathrm{p}=0.440$ & $\mathrm{p}=0.761$ & $\mathrm{p}=0.477$ & $\mathrm{p}=0.140$ & $\mathrm{p}=0.665$ & $\mathrm{p}=0.131$ & $\mathrm{p}=0.909$ \\
\hline & $\mathrm{q}=0.875$ & $\mathrm{q}=0.993$ & $\mathrm{q}=0.477$ & $q=0.541$ & $q=0.926$ & $q=0.639$ & $q=0.986$ \\
\hline \multirow{3}{*}{$\begin{array}{l}\text { Superior medial } \\
\text { frontal gyrus }\end{array}$} & $r(52)=-0.238$ & $t(51.15)=-1.20$ & $\mathrm{r}(60)=0.098$ & $r(67)=0.039$ & $r(60)=-0.015$ & $\mathrm{t}(39.40)=-0.771$ & $\mathrm{r}(54)=0.200$ \\
\hline & $\mathrm{p}=0.083^{*}$ & $\mathrm{p}=0.499$ & $\mathrm{p}=0.447$ & $\mathrm{p}=0.752$ & $\mathrm{p}=0.905$ & $\mathrm{p}=0.445$ & $\mathrm{p}=0.139$ \\
\hline & $\mathrm{q}=0.381$ & $q=0.993$ & $q=0.477$ & $q=0.903$ & $q=0.926$ & $q=0.739$ & $\mathrm{q}=0.418$ \\
\hline \multirow{3}{*}{ Middle frontal gyrus } & $\mathrm{r}(52)=0.076$ & $\mathrm{t}(50.71)=-0.92$ & $r(60)=0.107$ & $r(67)=0.068$ & $r(60)=0.029$ & $\mathrm{t}(49.53)=0.450$ & $\mathrm{r}(54)=0.002$ \\
\hline & $\mathrm{p}=0.584$ & $\mathrm{p}=0.890$ & $\mathrm{p}=0.410$ & $\mathrm{p}=0.580$ & $\mathrm{p}=0.820$ & $\mathrm{p}=0.655$ & $\mathrm{p}=0.985$ \\
\hline & $\mathrm{q}=0.875$ & $\mathrm{q}=0.993$ & $\mathrm{q}=0.477$ & $\mathrm{q}=0.871$ & $q=0.926$ & $\mathrm{q}=0.740$ & $\mathrm{q}=0.986$ \\
\hline \multirow{3}{*}{ Supplemental motor area } & $\mathrm{r}(52)=0.002$ & $\mathrm{t}(46.79)=-0.86$ & $r(60)=-0.142$ & $r(67)=0.163$ & $\mathrm{r}(60)=0.026$ & $\mathrm{t}(36.98)=-0.480$ & $\mathrm{r}(54)=0.308$ \\
\hline & $\mathrm{p}=0.988$ & $\mathrm{p}=0.663$ & $\mathrm{p}=0.271$ & $\mathrm{p}=0.180$ & $\mathrm{p}=0.841$ & $\mathrm{p}=0.635$ & $\mathrm{p}=0.021^{*}$ \\
\hline & $\mathrm{q}=0.988$ & $\mathrm{q}=0.993$ & $\mathrm{q}=0.477$ & $q=0.541$ & $q=0.926$ & $q=0.739$ & $q=0.126$ \\
\hline \multirow{3}{*}{ Medial orbitofrontal gyrus } & $\mathrm{r}(52)=-0.040$ & $\mathrm{t}(51.87)=-1.29$ & $\mathrm{r}(60)=0.093$ & $r(67)=0.009$ & $\mathrm{r}(60)=-0.012$ & $\mathrm{t}(36.22)=-1.268$ & $\mathrm{r}(54)=0.152$ \\
\hline & $\mathrm{p}=0.771$ & $\mathrm{p}=0.993$ & $\mathrm{p}=0.470$ & $\mathrm{p}=0.944$ & $\mathrm{p}=0.926$ & $\mathrm{p}=0.213$ & $\mathrm{p}=0.264$ \\
\hline & $\mathrm{q}=0.925$ & $\mathrm{q}=0.993$ & $q=0.477$ & $q=0.944$ & $q=0.926$ & $q=0.639$ & $q=0.527$ \\
\hline
\end{tabular}


medRxiv preprint doi: https://doi.org/10.1101/2021.06.02.21258020; this version posted June 9, 2021. The copyright holder for this preprint (which was not certified by peer review) is the author/funder, who has granted medRxiv a license to display the preprint in perpetuity.

It is made available under a CC-BY 4.0 International license .

Table 6. Associations between functional Asymmetry and cognitive domains. We report the Pearson's correlation coefficients, degrees of freedom, and p-values as well as the adjusted q-value from the FDR correction (correcting across six regions per set of tests). All domains are average z-scores across multiple tests (see methods).

\begin{tabular}{|c|c|c|c|c|c|}
\hline Region & Memory Learning & Memory Retrieval & Visuospatial & Language & Executive Attention \\
\hline \multirow{3}{*}{ Putamen } & $\mathrm{r}(60)=-0.119$ & $r(60)=-0.151$ & $\mathrm{r}(60)=0.157$ & $r(60)=-0.245$ & $\mathrm{r}(59)=0.009$ \\
\hline & $\mathrm{p}=0.358$ & $\mathrm{p}=0.240$ & $\mathrm{p}=0.224$ & $\mathrm{p}=0.055^{*}$ & $\mathrm{p}=0.943$ \\
\hline & $\mathrm{q}=0.755$ & $\mathrm{q}=0.830$ & $q=0.448$ & $\mathrm{q}=0.279$ & $\mathrm{q}=0.943$ \\
\hline \multirow{3}{*}{$\begin{array}{l}\text { Thalamus ventral } \\
\text { posterolateral nucleus }\end{array}$} & $\mathrm{r}(60)=0.023$ & $\mathrm{r}(60)=0.038$ & $\mathrm{r}(60)=-0.076$ & $\mathrm{r}(60)=-0.007$ & $\mathrm{r}(59)=0.212$ \\
\hline & $\mathrm{p}=0.861$ & $\mathrm{p}=0.772$ & $\mathrm{p}=0.558$ & $\mathrm{p}=0.957$ & $\mathrm{p}=0.100$ \\
\hline & $\mathrm{q}=0.915$ & $\mathrm{q}=0.830$ & $\mathrm{q}=0.670$ & $\mathrm{q}=0.957$ & $\mathrm{q}=0.270$ \\
\hline \multirow{3}{*}{$\begin{array}{l}\text { Superior medial } \\
\text { frontal gyrus }\end{array}$} & $\mathrm{r}(60)=0.161$ & $\mathrm{r}(60)=0.124$ & $\mathrm{r}(60)=0.201$ & $\mathrm{r}(60)=0.215$ & $r(59)=0.109$ \\
\hline & $\mathrm{p}=0.212$ & $\mathrm{p}=0.336$ & $\mathrm{P}=0.118$ & $\mathrm{p}=0.093^{*}$ & $\mathrm{p}=0.401$ \\
\hline & $q=0.755$ & $\mathrm{q}=0.830$ & $\mathrm{q}=0.448$ & $\mathrm{q}=0.279$ & $q=0.602$ \\
\hline \multirow{3}{*}{ Middle frontal gyrus } & $\mathrm{r}(60)=0.014$ & $r(60)=-0.050$ & $\mathrm{r}(60)=0.050$ & $r(60)=-0.058$ & $\mathrm{r}(59)=0.193$ \\
\hline & $\mathrm{p}=0.914$ & $\mathrm{p}=0.702$ & $\mathrm{p}=0.697$ & $\mathrm{p}=0.656$ & $\mathrm{p}=0.135$ \\
\hline & $\mathrm{q}=0.915$ & $\mathrm{q}=0.830$ & $\mathrm{q}=0.697$ & $\mathrm{q}=0.957$ & $\mathrm{q}=0.270$ \\
\hline \multirow{3}{*}{ Supplemental motor area } & $\mathrm{r}(60)=-0.021$ & $r(60)=-0.058$ & $r(60)=-0.172$ & $r(60)=-0.009$ & $\mathrm{r}(59)=0.045$ \\
\hline & $\mathrm{P}=0.871$ & $\mathrm{p}=0.656$ & $\mathrm{p}=0.181$ & $\mathrm{p}=0.945$ & $\mathrm{p}=0.729$ \\
\hline & $\mathrm{q}=0.915$ & $\mathrm{q}=0.830$ & $\mathrm{q}=0.448$ & $\mathrm{q}=0.957$ & $\mathrm{q}=0.875$ \\
\hline \multirow{3}{*}{ Medial orbitofrontal gyrus } & $\mathrm{r}(60)=0.114$ & $\mathrm{r}(60)=0.028$ & $\mathrm{r}(60)=0.130$ & $\mathrm{r}(60)=0.117$ & $\mathrm{r}(59)=0.245$ \\
\hline & $\mathrm{p}=0.378$ & $\mathrm{p}=0.830$ & $\mathrm{p}=0.314$ & $\mathrm{p}=0.364$ & $\mathrm{p}=0.057^{*}$ \\
\hline & $q=0.755$ & $q=0.830$ & $q=0.471$ & $q=0.728$ & $q=0.270$ \\
\hline
\end{tabular}

Table 7. Associations between functional absolute Asymmetry and cognitive domains. We report the Pearson's correlation coefficients, degrees of freedom, and p-values as well as the adjusted q-value from the FDR correction (correcting across six regions per set of tests). All domains are average z-scores across multiple tests (see methods).

\begin{tabular}{|c|c|c|c|c|c|}
\hline Region & Memory Learning & Memory Retrieval & Visuospatial & Language & Executive Attention \\
\hline \multirow{3}{*}{ Putamen } & $r(60)=-0.025$ & $\mathrm{r}(60)=0.002$ & $r(60)=-0.326$ & $r(60)=-0.326$ & $\mathrm{r}(59)=0.002$ \\
\hline & $\mathrm{p}=0.847$ & $\mathrm{p}=0.989$ & $\mathrm{p}=0.010^{*}$ & $\mathrm{p}=0.725$ & $P=0.985$ \\
\hline & $\mathrm{q}=0.847$ & $q=0.997$ & $q=0.059 *$ & $q=0.725$ & $\mathrm{q}=0.992$ \\
\hline \multirow{3}{*}{$\begin{array}{l}\text { Thalamus ventral } \\
\text { posterolateral nucleus }\end{array}$} & $r(60)=-0.317$ & $r(60)=-0.296$ & $\mathrm{r}(60)=-0.173$ & $\mathrm{r}(60)=-0.173$ & $r(59)=-0.323$ \\
\hline & $\mathrm{p}=0.012 *$ & $\mathrm{p}=0.019^{*}$ & $\mathrm{p}=0.178$ & $\mathrm{p}=0.279$ & $\mathrm{p}=0.011^{*}$ \\
\hline & $q=0.072 *$ & $\mathrm{q}=0.116$ & $\mathrm{q}=0.534$ & $\mathrm{q}=0.558$ & $q=0.066 *$ \\
\hline \multirow{3}{*}{$\begin{array}{l}\text { Superior medial } \\
\text { frontal gyrus }\end{array}$} & $\mathrm{r}(60)=0.084$ & $\mathrm{r}(60)=0.034$ & $\mathrm{r}(60)=0.069$ & $\mathrm{r}(60)=0.0688$ & $\mathrm{r}(59)=0.139$ \\
\hline & $\mathrm{p}=0.515$ & $\mathrm{P}=0.792$ & $\mathrm{p}=0.595$ & $\mathrm{p}=0.060^{*}$ & $\mathrm{p}=0.285$ \\
\hline & $q=0.707$ & $q=0.997$ & $q=0.714$ & $q=0.279$ & $q=0.571$ \\
\hline \multirow{3}{*}{ Middle frontal gyrus } & $\mathrm{r}(60)=-0.0118$ & $\mathrm{r}(60)=-0.215$ & $\mathrm{r}(60)=0.115$ & $\mathrm{r}(60)=0.115$ & $r(59)=-0.001$ \\
\hline & $\mathrm{p}=0.360$ & $\mathrm{p}=0.094^{*}$ & $\mathrm{p}=0.375$ & $\mathrm{p}=0.09^{*}$ & $\mathrm{p}=0.992$ \\
\hline & $q=0.707$ & $q=0.281$ & $q=0.608$ & $q=0.279$ & $q=0.993$ \\
\hline \multirow{3}{*}{ Supplemental motor area } & $r(60)=-0.070$ & $\mathrm{r}(60)=-0.000$ & $\mathrm{r}(60)=0.108$ & $\mathrm{r}(60)=0.108$ & $\mathrm{r}(59)=0.157$ \\
\hline & $\mathrm{p}=0.589$ & $\mathrm{p}=0.997$ & $\mathrm{p}=0.405$ & $\mathrm{p}=0.476$ & $\mathrm{P}=0.227$ \\
\hline & $q=0.707$ & $\mathrm{q}=0.997$ & $q=0.608$ & $\mathrm{q}=0.580$ & $q=0.571$ \\
\hline \multirow{3}{*}{ Medial orbitofrontal gyrus } & $\mathrm{r}(60)=0.124$ & $\mathrm{r}(60)=0.095$ & $\mathrm{r}(60)=0.033$ & $\mathrm{r}(60)=0.0328$ & $\mathrm{r}(59)=0.085$ \\
\hline & $P=0.337$ & $\mathrm{p}=0.462$ & $\mathrm{P}=0.800$ & $\mathrm{p}=0.483$ & $\mathrm{p}=0.514$ \\
\hline & $q=0.707$ & $q=0.926$ & $\mathrm{q}=0.800$ & $\mathrm{q}=0.580$ & $q=0.772$ \\
\hline
\end{tabular}




\section{DISCUSSION}

We identified regions with significant asymmetric activation during the face-name memory encoding task - four with left-hemispheric asymmetry: superior medial frontal gyrus, middle frontal gyrus, supplemental motor area, and the medial orbitofrontal gyrus and two with right-hemispheric asymmetry: putamen and ventral posterolateral nucleus of the thalamus. We found that greater left hemisphere asymmetry in the middle frontal gyrus was associated with greater cerebral glucose metabolism. We also found that better memory learning and executive attention performance was associated with more symmetric activation in the ventral posterolateral thalamus, while better visuospatial performance correlated with more symmetric activation in the putamen.

Our results are consistent with past work on putamen and thalamus asymmetry. Previous research has demonstrated that the right hemisphere of the putamen is associated with memory and visual imagery processing [23]. Based on this, we can cautiously interpret that more symmetric putamen activation may be associated with a compensatory mechanism (i.e., left hemispheric co-activation) that maintains greater visuospatial performance, whereas normally this activation may be right-hemispheric dominant, which was true in this sample on average. This region may help encode the visual imagery of the faces or even the face-name pairs. One study found that AD patients had greater left hemispheric atrophy compared to the right hemisphere in the thalamus compared to controls [11]. Our study with cognitively normal older adults found that greater thalamus symmetry was associated with greater memory learning and executive attention performance. Since the thalamus was found to have greater right hemisphere asymmetry, we can again speculate that symmetric activations may be associated with compensatory mechanisms that may maintain higher cognitive performance.

We found that greater left dominant activation in the middle frontal gyrus was positively correlated with greater whole-brain cerebral glucose metabolism. Previous research has shown that rightward lateralization of functional activity was associated with greater AD pathology [24, 25]. This region had largely left-hemisphere dominant activation and so its association with a marker of overall metabolism, which is a marker of brain health in the context of $\mathrm{AD}$, suggests that this region may play an important early role in AD. The middle frontal gyrus, which includes the dorsolateral prefrontal cortex, has been largely implicated in cognitive impairment, including AD [26].

By looking at effect sizes and directionality, we observed expected relationships between age, performance, and functional asymmetry. Although there was significant asymmetric activation in all six identified regions during the face-name task, there were no associations between activation asymmetry in these regions and any other AD risk factors. Our findings do not suggest any relationship between $A \beta$ and the functional asymmetry in older cognitively normal individuals. Thus, either $A ß$ is associated with regions that have non-significant asymmetry or may not have a large impact on asymmetry in the preclinical stage of $\mathrm{AD}$.

There is an ongoing question of how disease progression manifests in cortical versus subcortical brain structures $[27,28]$. In a longitudinal study, researchers identified significant putamen atrophy and right dominant asymmetry as people age [29]. Additionally, increased ventral posterolateral asymmetry in the thalamus has been noted to be associated with worse cognitive function [11]. These subcortical regions of the brain (i.e., thalamus and putamen) may be impacted earlier in $\mathrm{AD}$ [28], when excess $\mathrm{A} \beta$ production drives disease progression. One possible explanation could be that significant amyloid burden is interfering with the cortical communication pathway that goes through the subcortical regions like thalamus and putamen. Those with subcortical pathology may therefore have worse outcomes with greater asymmetry, meaning that cognitive reserve has been expended and compensatory mechanisms are no longer able to 
medRxiv preprint doi: https://doi.org/10.1101/2021.06.02.21258020; this version posted June 9, 2021. The copyright holder for this preprint (which was not certified by peer review) is the author/funder, who has granted medRxiv a license to display the preprint in perpetuity.

It is made available under a CC-BY 4.0 International license.

maintain cognitive function. We found that greater symmetry in the subcortical regions was associated with better cognitive performance. Unlike early-stage $\mathrm{AD}$, late-stage $\mathrm{AD}$ is linked closely with cytotoxic protein clearance and may impact cortical structures more than subcortical structures [27]. In late-onset AD, those who have retained leftward dominance despite pathology may have better disease outcomes. Thus, lower glucose metabolism may be correlated with more rightward asymmetry in cortical regions like the middle frontal gyrus.

Our study has several limitations. We analyzed data from the cross-sectional data and did not analyze longitudinal changes in asymmetry, $\mathrm{AD}$ factors, and cognitive domain scores during the memory encoding task. Longitudinal studies should address the temporal relationship between these factors by measuring for our predicted model of functional change, in which symmetry increases with age (i.e., more dedifferentiation) and then eventual rightward-dominant asymmetry occurs as Aß and WMHs increase and FDG, task performance, and cognitive domain scores decrease. Furthermore, we analyzed only regions of significant asymmetry during memory encoding - so there may be regions that have varying levels of asymmetry across participants that would not be detected since they on average do not show a significant asymmetry. Future studies should also explore the relationships between AD factors and greater variability in absolute asymmetry by considering all regions of the brain activated during a memory encoding task. To increase our understanding of the associations between asymmetry and AD risk factors, future studies should repeat this study with different functional tasks. We only investigated global differences in $A ß$ and glucose metabolism, however a regional approach may help us understand the regional impacts of $A ß$ and if, for instance, regional levels of $A ß$ asymmetry drive neural activation asymmetry.

This study supports previously identified relationships between brain asymmetry and neurodegenerative disease pathology. We found that greater left hemisphere asymmetry in the middle frontal gyrus was associated with greater cerebral glucose metabolism. In older cognitively normal adults, we did not identify an association between functional asymmetry and AD risk factors. However, our identification of associations between functional asymmetry and both cognitive function and glucose metabolism indicate that asymmetry may be associated with some early impairment, primarily glucose metabolism which may be an early indicator of preclinical disease. 


\section{References}

1. Tiwari, S., et al., Alzheimer's disease: pathogenesis, diagnostics, and therapeutics. Int J Nanomedicine, 2019. 14: p. 5541-5554.

2. Tosto, G., et al., Predicting Aggressive Decline in Mild Cognitive Impairment: The Importance of White Matter Hyperintensities. JAMA Neurology, 2014. 71(7): p. 872-877.

3. Svenningsson, A.L., et al., beta-amyloid pathology and hippocampal atrophy are independently associated with memory function in cognitively healthy elderly. Sci Rep, 2019. 9(1): p. 11180.

4. Edelman, K., et al., Amyloid-Beta Deposition is Associated with Increased Medial Temporal Lobe Activation during Memory Encoding in the Cognitively Normal Elderly. Am J Geriatr Psychiatry, 2017. 25(5): p. 551-560.

5. Cohen, A.D., et al., Basal cerebral metabolism may modulate the cognitive effects of Abeta in mild cognitive impairment: an example of brain reserve. J Neurosci, 2009. 29(47): p. 14770-8.

6. Dubois, B., et al., Preclinical Alzheimer's disease: Definition, natural history, and diagnostic criteria. Alzheimers Dement, 2016. 12(3): p. 292-323.

7. Cabeza, R., Hemispheric asymmetry reduction in older adults: the HAROLD model. Psychol Aging, 2002. 17(1): p. 85-100.

8. Park, D.C., et al., Aging reduces neural specialization in ventral visual cortex. Proc Natl Acad Sci U S A, 2004. 101(35): p. 13091-5.

9. Zaidel, E., Brain Asymmetry, in International Encyclopedia of the Social \& Behavioral Sciences, N.J. Smelser and P.B. Baltes, Editors. 2001, Pergamon: Oxford. p. 1321-1329.

10. Kong, X.Z., et al., Mapping cortical brain asymmetry in 17,141 healthy individuals worldwide via the ENIGMA Consortium. Proc Natl Acad Sci U S A, 2018. 115(22): p. E5154-e5163.

11. Low, A., et al., Asymmetrical atrophy of thalamic subnuclei in Alzheimer's disease and amyloidpositive mild cognitive impairment is associated with key clinical features. Alzheimers Dement (Amst), 2019. 11: p. 690-699.

12. Sarica, A., et al., MRI Asymmetry Index of Hippocampal Subfields Increases Through the Continuum From the Mild Cognitive Impairment to the Alzheimer's Disease. Front Neurosci, 2018. 12: p. 576.

13. Dolcos, F., H.J. Rice, and R. Cabeza, Hemispheric asymmetry and aging: right hemisphere decline or asymmetry reduction. Neuroscience \& Biobehavioral Reviews, 2002. 26(7): p. 819825.

14. Sperling, R., et al., Putting names to faces: successful encoding of associative memories activates the anterior hippocampal formation. NeuroImage, 2003. 20(2): p. 1400-1410.

15. Snitz, B.E., et al., Risk of progression from subjective cognitive decline to mild cognitive impairment: The role of study setting. Alzheimer's \& Dementia, 2018. 14(6): p. 734-742.

16. Nebes, R.D., et al., Cognitive aging in persons with minimal amyloid- $\beta$ and white matter hyperintensities. Neuropsychologia, 2013. 51(11): p. 2202-9.

17. Sperling, R.A., et al., Encoding novel face-name associations: a functional MRI study. Hum Brain Mapp, 2001. 14(3): p. 129-39.

18. Wu, M., et al., A fully automated method for quantifying and localizing white matter hyperintensities on MR images. Psychiatry Res, 2006. 148(2-3): p. 133-42.

19. Price, J.C., et al., Kinetic modeling of amyloid binding in humans using PET imaging and Pittsburgh Compound-B. Journal of Cerebral Blood Flow \& Metabolism, 2005. 25(11): p. 15281547.

20. Rolls, E.T., et al., Automated anatomical labelling atlas 3. Neuroimage, 2020. 206: p. 116189.

21. Benjamini, Y. and Y. Hochberg, Controlling The False Discovery Rate - A Practical And Powerful Approach To Multiple Testing. J. Royal Statist. Soc., Series B, 1995. 57: p. 289-300.

22. Seghier, M.L., Laterality index in functional MRI: methodological issues. Magn Reson Imaging, 2008. 26(5): p. 594-601. 
medRxiv preprint doi: https://doi.org/10.1101/2021.06.02.21258020; this version posted June 9, 2021. The copyright holder for this preprint

(which was not certified by peer review) is the author/funder, who has granted medRxiv a license to display the preprint in perpetuity.

It is made available under a CC-BY 4.0 International license.

23. Viñas-Guasch, N. and Y.J. Wu, The role of the putamen in language: a meta-analytic connectivity modeling study. Brain Struct Funct, 2017. 222(9): p. 3991-4004.

24. Weise, C.M., et al., Left lateralized cerebral glucose metabolism declines in amyloid-beta positive persons with mild cognitive impairment. Neuroimage Clin, 2018. 20: p. 286-296.

25. Frings, L., et al., Asymmetries of amyloid-beta burden and neuronal dysfunction are positively correlated in Alzheimer's disease. Brain, 2015. 138(Pt 10): p. 3089-99.

26. Kumar, S., et al., Extent of Dorsolateral Prefrontal Cortex Plasticity and Its Association With Working Memory in Patients With Alzheimer Disease. JAMA Psychiatry, 2017. 74(12): p. 12661274.

27. Frisoni, G.B., et al., The topography of grey matter involvement in early and late onset Alzheimer's disease. Brain, 2007. 130(Pt 3): p. 720-30.

28. Lee, E.C., et al., Association of Subcortical Structural Shapes With Tau, Amyloid, and Cortical Atrophy in Early-Onset and Late-Onset Alzheimer's Disease. Front Aging Neurosci, 2020. 12: p. 563559.

29. Raz, N., et al., Differential aging of the human striatum: longitudinal evidence. AJNR Am J Neuroradiol, 2003. 24(9): p. 1849-56. 